\title{
The Real Role of $\beta$-Blockers in Daily Cardiovascular Therapy
}

\author{
Csaba András Dézsi ${ }^{1} \cdot$ Veronika Szentes ${ }^{1}$
}

Published online: 29 March 2017

(C) The Author(s) 2017. This article is an open access publication

\begin{abstract}
The role of $\beta$-adrenoceptor antagonists ( $\beta$ blockers) in cardiovascular therapy has been subject to diverse trends and changes over the decades. With the advent of a wide variety of excellent drugs for the treatment of antihypertension, $\beta$-blockers have been relegated from the first-line treatment of essential hypertension. However, they remain the drugs of first choice in recommendations from the respective medical societies for heart failure, coronary artery disease, and atrial fibrillation as well as in hypertension complicated with heart failure, angina pectoris, or prior myocardial infarction. When indicated, cardioselective $\beta$-blockers should be prescribed in patients with diabetes mellitus or chronic obstructive pulmonary disease. We review the available evidence for the use of $\beta$-blockers in clinical conditions in which recommendations can be made for everyday practice.
\end{abstract}

Csaba András Dézsi

dcsa62@gmail.com

1 Department of Cardiology, Petz Aladár County Teaching Hospital, Vasvári Pál str. 2-4, 9024 Győr, Hungary

\section{Key Points}

$\beta$-Adrenoceptor antagonists ( $\beta$-blockers) are recommended for the first-line treatment of heart failure, coronary artery disease, and atrial fibrillation as well as of hypertension complicated with heart failure, angina pectoris, or prior myocardial infarction.

$\beta$-Blockers should not be withheld from patients with diabetes mellitus or chronic obstructive pulmonary disease, although cardioselective agents are preferable.

\section{Introduction}

Agents that block the adrenergic $\beta$-receptors have been used for decades in the treatment of cardiovascular disease (CVD). The development of primary prevention and earlydetection strategies as well as the emergence of new and effective therapeutic agents has seen the survival rates and life expectancy of patients with CVD increase considerably, with a consequent increase in the prevalence of these conditions [1]. Patients who develop a chronic heart disease usually need lifelong treatment, and finding the optimal personalized treatment for every patient is crucial.

According to new hypertension guidelines [2], $\beta$ blockers have been forced into the second line of therapeutic recommendations for essential hypertension, behind angiotensin-converting enzyme (ACE) inhibitors, angiotensin receptor blockers (ARBs), and calcium channel blockers (CCBs). These recommendations were based on meta-analyses reporting that $\beta$-blockers may be less 
Table 1 Characteristics of commonly used $\beta$-blockers

\begin{tabular}{|c|c|c|c|c|c|c|c|c|c|}
\hline Drug & $\begin{array}{l}\text { Indications in CVD } \\
\text { (other than }^{\text {hypertension }}{ }^{\mathrm{a}} \text { ) }\end{array}$ & $\begin{array}{l}\text { Daily dose } \\
\text { (mg/day) }\end{array}$ & $\begin{array}{l}\text { Half- } \\
\text { life } \\
\text { (h) }\end{array}$ & $\begin{array}{l}\text { Route of } \\
\text { excretion }\end{array}$ & $\begin{array}{l}\beta_{1^{-}} \\
\text {Selectivity }\end{array}$ & ISA & $\begin{array}{l}\alpha 1- \\
\text { Antagonist } \\
\text { activity }\end{array}$ & $\begin{array}{l}\text { Membrane } \\
\text { stabilizing } \\
\text { property }\end{array}$ & $\begin{array}{l}\text { Vasodilatory } \\
\text { action }\end{array}$ \\
\hline Acebutolol & $\begin{array}{l}\text { Chronic stable angina; } \\
\text { tachyarrhythmia }\end{array}$ & $200-1200$ & $3-4$ & $\begin{array}{l}\text { Renal } \\
\text { 30-40\%; } \\
\text { non-renal } \\
50-60 \%\end{array}$ & + & + & - & - & - \\
\hline Atenolol & $\begin{array}{l}\text { Chronic stable angina; } \\
\text { following MI; cardiac } \\
\text { arrhythmia }\end{array}$ & $50-100$ & $6-7$ & Mainly renal & + & - & - & - & - \\
\hline Bisoprolol & $\mathrm{HF}$ with reduced $\mathrm{EF}$ & $1.25-10$ & $9-12$ & $\begin{array}{l}\text { Renal } 50 \% \text {; } \\
\text { non-renal } \\
50 \%\end{array}$ & + & - & - & - & - \\
\hline Carvedilol & $\begin{array}{l}\text { Mild to severe HF; chronic } \\
\text { stable angina; following } \\
\text { MI }\end{array}$ & $3.125-100$ & $6-10$ & $\begin{array}{l}\text { Mainly non- } \\
\text { renal }\end{array}$ & - & - & + & + & + \\
\hline Metoprolol & $\begin{array}{l}\text { HF; chronic stable angina; } \\
\text { following MI; } \\
\text { tachyarrhythmia; }\end{array}$ & $50-450$ & $3-9$ & Mainly renal & + & - & - & + & - \\
\hline Nadolol & $\begin{array}{l}\text { Chronic stable angina; } \\
\text { tachyarrhythmia; } \\
\text { thyrotoxicosis }\end{array}$ & $20-240$ & $20-24$ & Mainly renal & - & - & - & - & - \\
\hline Nebivolol & Mild to moderate $\mathrm{HF}$ & $2.5-20$ & $12-19$ & $\begin{array}{l}38-67 \% \\
\text { renal; } \\
13-48 \% \\
\text { non-renal }\end{array}$ & + & + & - & - & + \\
\hline Propranolol & $\begin{array}{l}\text { Chronic stable angina; } \\
\text { following MI; cardiac } \\
\text { arrhythmias; thyrotoxicosis }\end{array}$ & $10-320$ & $3-6$ & $\begin{array}{l}10 \% \text { renal; } \\
90 \% \text { non- } \\
\text { renal }\end{array}$ & - & - & - & + & - \\
\hline
\end{tabular}

$C V D$ cardiovascular disease, $E F$ ejection fraction, $H F$ heart failure, $I S A$ intrinsic sympathomimetic activity, $M I$ myocardial infarction

${ }^{a}$ All listed drugs are indicated for the treatment of hypertension

favorable than some other drug classes for total mortality, cardiovascular (CV) events, and stroke outcomes. However, most of the analyzed data came from studies using atenolol and propranolol and may not apply to other agents $[2,3]$.

Treatment choices for patients with CVD should be based on the presence and magnitude of all risk factors and comorbid conditions as well as on the individual characteristics of the drugs in question (the primary characteristics of commonly used $\beta$-blockers are presented in Table 1). Compared with traditional $\beta$-blockers, newer agents with $\beta_{1}$ selectivity or vasodilating properties (such as carvedilol or nebivolol) reduce central pulse pressure and aortic stiffness more effectively than atenolol or metoprolol and tend to have fewer metabolic side effects $[2]$.

We present the available evidence for the use of $\beta$ blockers in relation to CVD. A comprehensive PubMed search was performed to identify relevant articles for discussion.

\section{B-Blockers in Heart Failure}

Heart failure (HF) is strongly correlated with hypertension: $75 \%$ of incident HF cases are preceded by elevated blood pressure [4]. $\beta$-Blockers reduce heart rate and blood pressure and have anti-arrhythmogenic and anti-ischemic effects [5]. Besides directly blocking sympathetic activity in the heart, they also inhibit ACE release from the juxtaglomerular apparatus [6]. In patients with HF, the action of $\beta$-blockers against the harmful effects of increased adrenergic activity (resulting from myocardial dysfunction) facilitates improvements in ventricular structure and function [5]. Long-term use of $\beta$-blockers in patients with HF has been shown to significantly improve hemodynamic parameters; $\beta$-blockade results in increased left ventricular stroke volume index and left ventricular ejection fraction (EF), reduced cardiac index, and decreased pulmonary artery and wedge pressure [7-11].

The use of a $\beta$-blocker along with an ACE inhibitor is recommended by the European Society of Cardiology 
(ESC) and American Heart Association (AHA) guidelines for all patients with systolic HF with reduced EF to prevent symptomatic HF, improve left ventricular remodeling, and reduce the risk of hospitalization and premature death (level I A evidence). Treatment should be started as soon as possible after diagnosis. In coexisting atrial fibrillation (AF), a $\beta$-blocker should be the first-line treatment to control the ventricular rate (level I A evidence); in all patients with a recent or remote history of myocardial infarction (MI) or acute coronary syndrome (ACS) and reduced $\mathrm{EF}$, a $\beta$-blocker should be used to reduce mortality (level I B evidence) [12, 13]. According to the ESC guideline on peripheral artery disease, $\beta$-blockers are not contraindicated in patients with lower extremity artery disease (LEAD) and should be considered in concomitant HF (level IIa B evidence) [14].

\subsection{Heart Failure with Reduced Ejection Fraction}

Recommendations for the use of $\beta$-blockers in HF with reduced EF are mainly based on the outcomes of large randomized placebo-controlled trials investigating bisoprolol (CIBIS-II), carvedilol (COPERNICUS), metoprolol (MERIT-HF), and nebivolol (SENIORS) (see Table 2 for the full names of trials mentioned in this article) [12, 13]. These trials have shown the investigated $\beta$-blockers to effectively reduce the risk of mortality and admission to hospital (Table 3) [15, 16]. These results verified earlier findings from randomized studies, meta-analyses of which found that the reduction in mortality risk was $>30 \%$ with the use of $\beta$-blockers $[9,19,20]$. A recent network metaanalysis of 21 randomized controlled trials (RCTs) further confirmed approximately the same reduction in all-cause mortality risk. The effect sizes were consistent when comparing trials with shorter and longer ( $>12$ months) follow-up durations. $\beta$-Blockers also significantly reduced deaths from CVD as well as sudden deaths. Head-to-head comparisons of individual $\beta$-blockers did not show significant differences in the evaluated outcomes, suggesting a strong class effect [7].

There may be individual differences between different $\beta$-blockers with regard to clinical outcomes in HF with reduced EF, as suggested by some comparative studies. The COMET investigators found a significant difference in all-cause mortality rate with carvedilol versus bisoprolol [hazard ratio $(\mathrm{HR}) 0.83 ; p=0.0017$ ) [21]. In a retrospective cohort, carvedilol and bisoprolol but not metoprolol significantly reduced the risk of death and hospitalization

Table 2 Acronyms and full names of trials mentioned in this article

\begin{tabular}{|c|c|}
\hline Short name & Full name \\
\hline $\mathrm{AF}-\mathrm{CHF}$ & Atrial Fibrillation and Congestive Heart Failure \\
\hline AFFIRM & The Atrial Fibrillation Follow-up Investigation of Rhythm Management \\
\hline BEST & Beta-Blocker Evaluation in Survival Trial \\
\hline BHAT & Beta Blocker Heart Attack Trial \\
\hline BIP & Bezafibrate Intervention Study \\
\hline CAPRICORN & Carvedilol Post-Infarct Survival Control in Left Ventricular Dysfunction \\
\hline CHARISMA & Clopidogrel for High Atherothrombotic Risk and Ischemic Stabilization, Management, and Avoidance \\
\hline CIBIS-II & Cardiac Insufficiency Bisoprolol Study \\
\hline COMET & Carvedilol Or Metoprolol European Trial \\
\hline COMMIT & Clopidogrel and Metoprolol in Myocardial Infarction Trial \\
\hline COPERNICUS & Carvedilol Prospective Randomized Cumulative Survival \\
\hline ISIS-1 & First International Study of Infarct Survival \\
\hline J-DHF & Japanese Diastolic Heart Failure Study \\
\hline MERIT-HF & Metoprolol CR/XL Randomised Intervention Trial in Congestive Heart Failure \\
\hline MIAMI & Metoprolol in acute myocardial infarction \\
\hline MOCHA & Multicenter Oral Carvedilol Heart Failure Assessment \\
\hline MUSTT & Multicenter Unsustained Tachycardia Trial \\
\hline PRECISE & Percutaneous Robotically Enhanced Coronary Intervention \\
\hline SENIORS & Study of Effects of Nebivolol Intervention on Outcomes and Rehospitalization in Seniors With Heart Failure \\
\hline UKPDS & UK Prospective Diabetes Study \\
\hline$\beta$-PRESERVE & Rationale and design of the $\beta$-blocker in heart failure with normal left ventricular ejection fraction \\
\hline
\end{tabular}


Table 3 Outcomes of major randomized, placebo-controlled trials in patients with heart failure and reduced ejection fraction

\begin{tabular}{|c|c|c|c|c|c|c|}
\hline Trial & $\beta$-Blocker & $N$ & $\begin{array}{l}\text { Mean } \\
\text { duration }\end{array}$ & $\mathrm{EF}$ & Primary endpoints & Main outcomes \\
\hline \multirow[t]{2}{*}{ CIBIS-II [15] } & \multirow[t]{2}{*}{ Bisoprolol } & \multirow[t]{2}{*}{2647} & \multirow[t]{2}{*}{1.3 years } & \multirow[t]{2}{*}{$\leq 35 \%$} & All-cause mortality & $\begin{array}{l}11.8 \text { vs. } 17.3 \% \text { (HR } 0.66 \\
p<0.0001)\end{array}$ \\
\hline & & & & & Sudden death & $\begin{array}{l}3.6 \text { vs. } 6.3 \%(\mathrm{HR} 0.56 \\
\quad p=0.0011)\end{array}$ \\
\hline \multirow[t]{2}{*}{$\begin{array}{l}\text { COPERNICUS } \\
{[16]}\end{array}$} & \multirow[t]{2}{*}{ Carvedilol } & \multirow[t]{2}{*}{2289} & \multirow[t]{2}{*}{10.4 months } & \multirow[t]{2}{*}{$<25 \%$} & $\begin{array}{l}\text { Combined risk of death or } \\
\text { hospitalization for CV reasons }\end{array}$ & $\begin{array}{c}\text { Cumulative risk } 41.6 \text { vs. } \\
30.2 \%(p=0.00002)\end{array}$ \\
\hline & & & & & $\begin{array}{l}\text { Combined risk of death or } \\
\text { hospitalization for } \mathrm{HF}\end{array}$ & $\begin{array}{l}\text { Cumulative risk } 37.9 \text { vs. } \\
25.5 \%(p=0.000004)\end{array}$ \\
\hline $\begin{array}{l}\text { MERIT-HF } \\
\text { [17] }\end{array}$ & Metoprolol & 3991 & 1 year & $\leq 40 \%$ & $\begin{array}{l}\text { Combined total mortality or all- } \\
\text { cause hospitalization }\end{array}$ & $\begin{array}{l}\text { Risk reduction } 19 \% \\
\quad(p<0.001)\end{array}$ \\
\hline \multirow[t]{2}{*}{ SENIORS [18] } & \multirow[t]{2}{*}{ Nebivolol } & \multirow[t]{2}{*}{2128} & \multirow[t]{2}{*}{21 months } & \multirow[t]{2}{*}{$\begin{array}{l}\leq 35 \% \text { in } 65 \% \text { of pts; } \\
>35 \% \text { in } 35 \% \text { of pts }\end{array}$} & $\begin{array}{l}\text { Death or hospitalization for } \mathrm{CV} \\
\text { reasons }\end{array}$ & $\begin{array}{l}31.1 \text { vs. } 35.3 \% \text { (HR } 0.86 ; \\
\quad p=0.039)\end{array}$ \\
\hline & & & & & All-cause mortality & $\begin{array}{l}15.8 \text { vs. } 18.1 \%(\text { HR } 0.88 \\
\quad p=0.21)\end{array}$ \\
\hline
\end{tabular}

$C V$ cardiovascular, $E F$ ejection fraction, $H F$ heart failure, $H R$ hazard ratio, pts patients

for HF [22]. Studies of carvedilol also suggested a doserelated benefit for the improvement of EF and cardiovascular hospitalization and mortality rates [23, 24].

Continuation of previous $\beta$-blocker therapy after discharge seems to be beneficial after acute decompensated HF: the use of $\beta$-blockers both before admission and after discharge was associated with lower 31- and 180-day mortality in patients with acute decompensation receiving $\beta$-blockers than in those who did not receive $\beta$-blocker therapy $(p<0.0001)$ [25].

A genetic component also influences responsiveness to pharmacotherapy with $\beta$-blockers. For example, evidence indicates that African-American patients with HF with the GRK5 Gln41Gln genotype (and in the case of bucindolol, also with the ADRB1 Arg389Arg genotype) especially benefit from $\beta$-blockade [26].

\subsection{Heart Failure with Preserved Ejection Fraction}

The ESC and AHA guidelines primarily recommend the use of $\beta$-blockers for the control of ventricular rate in HF with preserved EF [12, 13].

The J-DHF trial found a favorable effect with standard doses of carvedilol $>7.5 \mathrm{mg} /$ day on the endpoints of CVD and unplanned hospitalization for any $\mathrm{CV}$ causes compared with the control group $(p=0.0356)$. However, carvedilol did not improve prognosis in smaller doses or in terms of the primary outcome [27]. A predefined sub-analysis of SENIORS also found a beneficial effect from the $\beta_{1}$-selective nebivolol in elderly patients with $\mathrm{HF}$ and impaired and preserved $\mathrm{EF}$ on the primary endpoint of all-cause mortality or CV hospitalization [28].
Meta-analyses of observational studies with follow-up periods ranging mostly from 1 to 5 years have shown an association between $\beta$-blockers and a significant (9-19\%) reduction in the relative risk (RR) of all-cause mortality in patients with HF and preserved EF. However, the hospitalization rate for HF was not affected [29, 30].

These results also suggest a protective effect from $\beta$ blocker use in this population, and the ongoing prospective RCT of metoprolol, $\beta$-PRESERVE, will hopefully provide enough information to enable a recommendation on the matter [31].

\subsection{Heart Failure and Chronic Kidney Disease}

The beneficial effect of $\beta$-blockers on mortality and hospitalization risk can also be seen in patients with HF with reduced $\mathrm{EF}$ and co-existent chronic kidney disease (CKD). A meta-analysis of six trials comparing bisoprolol, carvedilol, metoprolol, nebivolol, and acebutolol versus placebo found a significant reduction of all-cause and cardiovascular mortality (by 28 and 34\%, respectively) [32]. A post hoc analysis of the CAPRICORN and COPERNICUS trials in patients with systolic left ventricular dysfunction also found that patients with mild to moderate CKD benefited from $\beta$-blocker therapy: carvedilol treatment decreased the risks of all-cause, $\mathrm{CV}$, and HF mortality as well as the risk of first hospitalization for $\mathrm{HF}$ and the composite of $\mathrm{CV}$ mortality or HF hospitalization [33]. The CIBIS-II trial investigated patients with $\mathrm{HF}$ and reduced $\mathrm{EF}$ and found the beneficial effect of bisoprolol on all-cause mortality and hospitalization due to HF to be consistent irrespective of the stage of CKD, defined by the estimated glomerular 
filtration rate (eGFR). The absolute benefit of bisoprolol was greater for patients with $\mathrm{HF}$ and deteriorated renal function than for those without [34].

\section{3 ß-Blockers in Coronary Artery Disease}

The majority of CV-related deaths are associated with coronary artery disease (CAD). The last few decades has seen a decline in CV mortality rates and a parallel increase in prevalence rates, largely because of the increased survival rates and life expectancy of these patients [35].

The anti-anginal effect of $\beta$-blockers is mainly based on their negative inotropic and chronotropic properties. The decreased heart rate lessens the myocardial oxygen demand. By prolonging the diastolic filling time and increasing vascular resistance in non-ischemic areas, $\beta$ blockers increase coronary perfusion of the ischemic areas and improves the contractility of viable but hibernating myocardial regions. The prevention of myocardial wall stress might also contribute to the prevention of myocardial rupture [5, 36, 37].

In patients with angina pectoris, $\beta$-blockers remain the standard of care for the relief of symptoms and secondary prevention of $\mathrm{CV}$ events. The AHA and ESC guidelines recommend the first-line use of $\beta$-blockers in stable CAD for heart rate and symptom control (level IA evidence) and in patients with hypertension with chronic stable angina and a history of prior MI (level IA evidence). $\beta$-Blocker therapy should also be considered in asymptomatic patients with large areas of ischemia (level IIa C evidence) and in microvascular angina to improve effort-related angina symptoms (level I B evidence) [37, 38]. According to the ESC guideline on peripheral artery diseases, $\beta$-blockers are not contraindicated in patients with LEAD and should be considered in those with CAD (level IIa B evidence) [14]. The most frequently used agents for the management of CAD are cardioselective $\beta_{1}$-blockers without intrinsic sympathomimetic activity (ISA) [37].

\subsection{Stable Angina Pectoris}

The use of $\beta$-blockers in patients with CAD was shown to significantly improve exercise parameters such as time to onset of ST-segment depression and angina, total exercise time, and total workload. They can also reduce symptomatic and asymptomatic ischemic episodes during daily activities [39-41]. In patients with stable angina without prior MI, $\beta$-blockers are mainly used for the relief of angina symptoms and reduction of the ischemic burden. No evidence is available from RCTs to support a mortality benefit with $\beta$-blockers in patients with stable angina pectoris without MI [42, 43]. A recent meta-analysis of relevant $\beta$-blocker trials in patients with stable angina did not find a significant impact of $\beta$-blockers on mortality in general but suggested a trend for cardioselective $\beta$-blockers to improve survival rates [44].

\subsection{Myocardial Infarction}

In the early large placebo-controlled RCTs in MI (including the BHAT, the Norwegian Multicenter Study Group Trial, and the Göteborg Trial), administration of $\beta$-blockers in patients after a recent MI reduced total mortality by 25-35\% [45-47]. In the first week after MI, atenolol significantly reduced mortality by about $15 \%$ compared with placebo in the ISIS-1 trial. Overall vascular mortality was also significantly lower (approximately 12\%) in the atenolol group after 1 year [48]. The meta-analysis of 22 longterm RCTs in MI confirmed the survival benefits of $\beta$ blocker use with a $23 \%$ relative reduction in mortality [49]. Meta-analyses of available RCTs found a mortality reduction of about $8-13 \%$ with administration of intravenous $\beta$-blocker within $24 \mathrm{~h}$ of acute MI $[36,50]$.

$\beta$-Blockers seem to have a protective effect for the recurrence of ischemic events. The post hoc analysis of the CHARISMA trial found a lower risk of recurrent infarction (HR $0.62 ; p=0.049$ ) in patients with prior MI receiving $\beta$ blocker therapy [42]. Early intravenous administration of $\beta$-blockers might further protect from recurrent ischemic events. Early compared with delayed administration of metoprolol was associated with decreased incidence of reinfarction ( 2.7 vs. $5.1 \% ; p=0.02)$ and recurrent ischemic events (18.8 vs. $24.1 \% ; p<0.02)$, although it did not improve ventricular function or mortality rates [51]. The COMMIT trial, investigating early intravenous and subsequent oral metoprolol therapy in 45,852 patients with MI, showed that early $\beta$-blocker use reduced the risk of both reinfarction [odds ratio $(\mathrm{OR}) 0.82 ; p=0.001]$ and ventricular fibrillation (OR $0.83 ; p=0.001$ ) [52]. A recent metaanalysis of 16 RCTs with early intravenous $\beta$-blocker use also confirmed a significant risk reduction for myocardial re-infarction (RR 0.73; $p=0.004$ ) [50].

Although the study results from COMMIT confirmed a reduced risk of re-infarction and AF, they also suggested an elevated risk of cardiogenic shock with the use of $\beta$ blockers. The excess risk of shock (OR 1.30; $p<0.00001$ ) was mainly observed in the first $24 \mathrm{~h}$ and was particularly high in patients aged $\geq 70$ years, in those with systolic blood pressure $<120 \mathrm{mmHg}$, those with a heart rate $>110$ beats per minute, and those in Killip class III [52]. A meta-analysis of 16 studies with early administration of $\beta$ blockers did not confirm the above findings, showing no increase in the risk of cardiogenic shock [RR 1.02, 95\% confidence interval (CI) $0.77-1.35, p=0.91$ ] [50]. Nevertheless, caution in initiating $\beta$-blocker therapy is 
reasonable when treating high-risk patients after an MI and those at higher risk of developing cardiogenic shock.

\subsection{Coronary Artery Disease and Heart Failure}

$\beta$-Blocker agents have considerable beneficial effects in patients with $\mathrm{HF}$ and reduced EF after an acute MI. In the CAPRICORN study, carvedilol significantly reduced the risk of all-cause and cardiovascular mortality (HR 0.77, $p=0.031$; HR $0.74, p=0.024)$ and the recurrence of nonfatal MI (HR 0.71, $p=0.002)$ compared with placebo [53]. A sub-analysis of SENIORS found a similar $32 \%$ reduction in the risk of ischemic events in those with HF and CAD treated with nebivolol after 2 years of follow-up [54]. The MUSTT investigators also reported a similar reduction in the 5 -year mortality risk with $\beta$-blocker use in patients with CAD and reduced EF (HR 0.63-0.72, $p<0.0001)$ [55].

Patients with $\mathrm{HF}$ and preserved EF after MI may also benefit from oral $\beta$-blockers. A recent meta-analysis of seven observational studies found a reduction in all-cause mortality (HR 0.79 , 95\% CI 0.65-0.97) in patients receiving oral $\beta$-blocker therapy after MI treated with percutaneous coronary intervention [56].

\section{4 -Blockers in Atrial Fibrillation}

The most common risk factors for developing AF are hypertension, valvular disease, ischemic cardiomyopathy, diabetes mellitus, and thyroid disease, with the majority of patients having one or more of these conditions [57].

Agents antagonizing $\beta$-adrenergic receptors (also known as class II antiarrhythmic drugs) decrease sympathetic activity on the heart and prolong atrioventricular nodal conduction time and refractoriness. These actions result in a decreased ventricular rate in patients with $\mathrm{AF}$ and in the ability to prevent the AF recurrence [58].

The ESC and AHA guidelines recommend patients with AF be treated to achieve acute rate control and to regulate inappropriate ventricular rate or irregular rhythm as they can cause severe hemodynamic distress (level I A evidence). Intravenous $\beta$-blocker use is recommended to slow the ventricular heart rate in acute $\mathrm{AF}$ in stable patients without pre-excitation (level I A-B evidence). Oral $\beta$ blocker therapy is among the recommended measures to slow the ventricular response in patients with paroxysmal, persistent, or permanent AF (level I A-B evidence). $\beta$ Blockers are also recommended to prevent recurrent $\mathrm{AF}$ in hypertrophic cardiomyopathy and to control ventricular rate in HF, in ACS, and in patients with hyperthyroidism $[59,60]$.

\subsection{Rate Control}

Robust data from the AFFIRM trial confirmed $\beta$-blockers as the most effective drugs for rate control in patients with $\mathrm{AF}(p<0.0001)$, with overall rate control achieved in $70 \%$ of the patients who received a $\beta$-blocker compared with treatment initiation with a $\mathrm{CCB}$ or digoxin. Rate control was considered achieved when the average resting heart rate was $\leq 80$ beats per minute and either stayed $\leq 100$ for $24 \mathrm{~h}$ of monitoring or did not reach 110 beats per minute after 6 min of walking [61].

A non-interventional study of patients with AF found the risk of mortality to be lower for patients receiving ratecontrol treatment with $\beta$-blockers (HR 0.76; 95\% CI 0.74-0.78) compared with the control group, who did not receive any rate-control drug [62].

A number of trials have demonstrated benefits such as moderate heart rate and rate control with $\beta$-blocker treatment in patients with HF and AF. However, the role of $\beta$ blockers has been debated in concomitant $\mathrm{HF}$ and $\mathrm{AF}$ after a meta-analysis of the Beta-Blockers in Heart Failure Collaborative Group failed to show mortality reduction in this population [63].

The BEST trial, which investigated bucindolol, showed that, in patients with $\mathrm{HF}$ and reduced $\mathrm{EF}$ and $\mathrm{AF}$, those receiving $\beta$-blocker therapy were more likely to achieve a resting heart rate $\leq 80$ beats per minute. In all patients (with or without $\mathrm{AF}$ ), a resting heart rate $\leq 80$ beats per minute was correlated with a decreased risk of cardiovascular mortality (HR 0.61, $p=0.025$ ) and cardiovascular hospitalization (HR $0.79, p=0.002$ ) [64]. In the recently published AF-CHF substudy, $\beta$-blocker use was also associated with significantly lower all-cause mortality in those with HF and AF (RR 0.72, $p=0.018$ ), although no effect was seen in hospitalization rate [65]. In patients with $\mathrm{HF}$ and reduced EF from the Swedish Heart Failure Registry trial, $\beta$-blocker use was associated with reduced allcause mortality in patients with or without AF. A higher resting heart rate was associated with increased mortality in sinus rhythm and also in AF in patients when heart rate exceeded $>100$ beats per minute [66].

Multivariate analysis of the CIBIS-II data also showed a significant decrease of heart rate with bisoprolol compared with placebo and an increasing mortality benefit in patients with sinus rhythm with both lower baseline heart rates and greater heart rate reductions during follow-up. However, no mortality benefit was found in patients with AF [67]. The meta-analysis of ten RCTs by the Beta-Blockers in Heart Failure Collaborative Group showed similar results, with a significant reduction in all-cause mortality in patients with sinus rhythm (HR $0.73,95 \%$ CI $0.67-0.80, p<0.001$ ) but not in patients with AF [68]. 
The prospective RCT RATE-AF trial will evaluate various effects of initial rate control therapy with bisoprolol versus digoxin in permanent AF [69].

\subsection{Prevention of Recurrent Atrial Fibrillation}

The other goal of $\beta$-blocker use is to prevent the recurrence of AF. After 6 months of follow-up, metoprolol use was shown to significantly decrease the recurrence of AF compared with placebo in patients enrolled after cardioversion of persistent AF. In those who had a relapse, heart rate was significantly lower in the metoprolol group [70].

In the post hoc analysis of the MERIT-HF study, $\beta$ blocker use in patients with HF significantly reduced the risk of new-onset AF compared with placebo (RR 0.53; $p=0.0005$ ) [71]. A meta-analysis of seven HF trials also found that $\beta$-blockers significantly reduced the occurrence of AF, with an RR reduction of $27 \%(p<0.001)$ [72]. The BEST genetic substudy revealed that only patients with HF with the Arg389Arg genotype experienced a considerable risk reduction for new-onset AF when using bucindolol. The ongoing GENETIC-AF study will investigate the effect of bucindolol versus metoprolol use in ADRB1 Arg389Arg homozygous patients and hopefully shed more light on the pharmacogenomic aspects of $\beta$-blockade [26]. In terms of survival, data from the COMET study indicated that new-onset AF is an independent predictor of long-term all-cause mortality in patients with HF [73].

In patients after MI with left ventricular dysfunction, $\beta$ blocker use substantially reduced the incidence of AF or flutter (HR 0.41; $p=0.0003$ ); the corresponding risk of ventricular tachyarrhythmia was even lower (HR 0.24; $p<0.0001)$ [74].

$\beta$-Blockers effectively prevent postoperative AF, the most common complication of cardiac surgery. Robust meta-analyses of RCTs found a risk reduction of AF after cardiac surgery of 66-74\% with $\beta$-blockers [75-78]. Advantages of perioperative use of $\beta$-blockers in non-cardiac surgery are less clear. Systematic reviews have shown that, although $\beta$-blockers significantly reduced the occurrence of $\mathrm{AF}$, myocardial ischemia, and acute $\mathrm{MI}$, they may also incur a potential increase in all-cause mortality and cerebrovascular events [79, 80].

\subsection{Atrial Fibrillation and Hyperthyroidism}

Atrial fibrillation is a common finding in hyperthyroid states (encountered in $10-15 \%$ of the patients) [81]. In those with thyrotoxicosis, treatment with $\beta$-blockers not only significantly decreased heart rate and systolic blood pressure but also improved other hyperadrenergic symptoms such as muscle weakness, tremor, degree of irritability, emotional lability, and exercise intolerance [82-85].

\section{5 $\beta$-Blockers in Diabetes Mellitus and Metabolic Syndrome}

Diabetes mellitus (DM) and obesity are highly correlated with CVD and associated with an increased risk of developing major $\mathrm{CV}$ events, including $\mathrm{CAD}$, stroke, and $\mathrm{HF}$; the risk is further exacerbated in those with concomitant hypertension. Both metabolic syndrome and DM are associated with high adrenergic drive and cardiac output, resulting in myocardial and vascular damage. Consequently, the risk of mortality due to heart disease and ischemic heart disease is two to four times higher for patients with DM than for those without [86-88].

Despite the supporting facts and guidelines, there is still reluctance to prescribe $\beta$-blockers in patients with DM and CVD, especially among patients with the most severe, high-risk disease, who could benefit the most from appropriate therapy [89, 90].

Concerns have been raised regarding the use of $\beta$ blockers in the diabetic population or in those at increased risk of DM due to a possible deteriorating metabolic influence of some of these agents. Furthermore, the risk of prolonged hypoglycemia was hypothesized to be higher with non-selective $\beta$-blockade in patients using insulin or sulfonylureas. However, no significant difference could be seen in the risk of hypoglycemia with $\beta$-blockers in a cohort of 13,559 elderly patients with DM compared with non-users. Only a non-significant trend favoring cardioselective over non-selective $\beta$-blockers was registered $[86,91]$.

Metabolic changes attributable to $\beta$-blockers may include elevation of blood sugar and glycated hemoglobin $\left(\mathrm{HbA}_{1 \mathrm{c}}\right)$ levels, worsening of insulin sensitivity, and changes in triglyceride and lipoprotein levels and seem to be mainly associated with $\beta_{2}$ and $\beta_{3}$ receptor blockade $[86,92]$. Consequently, while non-selective agents may cause deterioration of metabolic parameters, these disturbances are observed to a much lesser extent with $\beta_{1}$-selective agents (e.g., atenolol or bisoprolol) and cannot be observed with vasodilator agents, including those with intrinsic $\beta_{2}$ sympathomimetic activity (e.g., nebivolol) or triggering $\alpha$-blockade (e.g., carvedilol) [86, 91, 93-99].

According to the ESH/ESC guidelines, all classes of antihypertensive agents are recommended and can be used in patients with hypertension and DM (level I A evidence). In those with metabolic syndrome, antihypertensive agents that potentially improve or at least do not worsen insulin sensitivity (including vasodilating $\beta$-blockers) should be considered (level IIa C evidence) [2]. The ESC guidelines 
do not contraindicate $\beta$-blocker use for hypertension in patients with LEAD and DM, based on the finding that $\beta$ blockers do not adversely affect walking capacity or symptoms of intermittent claudication in patients with mild-to-moderate LEAD [2, 14]. Evidence on the use of various anti-hypertensive drugs in peripheral artery disease is generally poor. Therefore, careful consideration of individual patient therapy should be made on a case-bycase basis.

The American Association of Clinical Endocrinologists (AACE) guidelines find $\beta$-blockers to be less appealing for first-line treatment of hypertension in patients with DM (grade A recommendation). The use of third-generation $\beta$ blockers that cause vasodilatation and an increase in insulin sensitivity (such as nebivolol or carvedilol) seem to be particularly beneficial (grade A recommendation) [100].

In DM with systolic HF, a $\beta$-blocker is recommended to reduce mortality and hospitalization according to the joint ESC/EASD guidelines (level I A evidence). In DM with an ACS, $\beta$-blockers should be considered to reduce mortality and morbidity (level IIa B evidence). $\beta$-Blockers are also recommended in both $\mathrm{HF}$ and after acute $\mathrm{MI}$ to prevent sudden cardiac death in patients with DM (level I A evidence) [101].

\subsection{Diabetes Mellitus and Hypertension}

Although the use of $\beta$-blockers has been associated with an increased risk of developing type $2 \mathrm{DM}$, the influence of adverse metabolic effects seems to be much smaller in those with established and adequately treated DM compared with the several benefits of blood pressure control in those with concomitant hypertension [101-103].

A sub-study of the UKPDS evaluated the long-term impact of blood pressure control in hypertension and with DM. The use of atenolol or captopril significantly reduced the risk of fatal $(32 \%)$ and non-fatal (24\%) macrovascular and microvascular complications over 9 years of follow-up in the tight blood pressure control group (aiming for a blood pressure of $<150 / 85 \mathrm{mmHg}$ ), with equal efficacy between the agents studied. The trial not only found mortality and morbidity benefits of a $\beta_{1}$-selective blocker to be similar to those of an ACE inhibitor in patients with DM but also found that tight blood pressure control may be more important than glycemic control in protecting these patients against macrovascular and microvascular disease as well as possibly considerably improving their survival [103, 104].

\subsection{Diabetes Mellitus and Heart Failure}

Meta-analyses of major HF trials (Australia/New Zealand Heart Failure Research Collaborative Group, BEST,
CAPRICORN， CIBIS-II， COPERNICUS, MERIT-HF, MOCHA, PRECISE, US Carvedilol Trials) indicate a similar and significant survival benefit with $\beta$-blockers compared with placebo in diabetic and non-diabetic populations (ranging from 16 to $28 \%$ and from 28 to $37 \%$, respectively), with consistently overlapping $95 \%$ CIs of risk ratios through the analyses. The relative reduction in mortality shows a less favorable trend for patients with diabetes compared with those without. However, as the absolute risk of mortality is considerably greater in patients with DM, the absolute mortality benefit should be equal or even greater for those with DM [87, 105-107]. Subgroup analyses of individual major HF trials also show a similar reduction in hospitalization and improvement of symptoms in those with and without DM [15, 108-110].

\subsection{Diabetes Mellitus and Myocardial Infarction}

In post-MI patients with DM, $\beta$-blockers were shown to reduce the risk of late infarction, sudden death, and arrhythmias and to improve mortality according to retrospective analyses of the MIAMI study and the Göteborg Metoprolol Trial [111]. Data from a multicenter cohort of 2024 patients indicated that $\beta$-blocker use is an independent predictor of 1-year cardiac survival following hospital discharge for post-MI patients with DM. Patients with DM receiving $\beta$-blocker therapy had a mortality of $10 \%$ compared with $23 \%$ for those who did not receive a $\beta$-blocker [112]. In a retrospective analysis of patients with CAD and non-insulin-dependent DM from the BIP study, those receiving $\beta$-blocker therapy had a reduced mortality risk ( $\operatorname{RR} 0.58 ; p=0.0001)$ after 3 years of follow-up than those without $\beta$-blocker medication [113].

A large observational study including 59,445 patients with DM showed a $36 \%$ mortality reduction 2 years after MI in those treated with a $\beta$-blocker. The mortality reduction in patients with no complications was $40 \%$. Again, though the relative benefit compared with patients without DM seems to be somewhat smaller, due to the high mortality rate among patients with DM after $\mathrm{MI}$, the absolute survival benefit is expected to be much larger in patients with DM [87, 89].

\section{6 -Blockers in Chronic Obstructive Pulmonary Disease and Bronchial Asthma}

Cardiovascular disease frequently coexist with chronic obstructive pulmonary disease (COPD). However, $\beta$ blockers are substantially underused in patients with both COPD and CVD for fear of adverse pulmonary effects, especially in advanced COPD [114, 115]. $\beta$-Blockers are 
generally considered to be contraindicated in patients with bronchial asthma [116].

Because of the very sensitive feedback mechanism of the adrenergic system, chronic use of $\beta$-blockers sensitizes the $\beta_{2}$ receptors to further stimulation by increasing receptor density in target tissues. Consequently, $\beta$-blockers may even improve the effectiveness of $\beta_{2}$ agonists during an exacerbation of reactive airway disease by potentiating their bronchodilator effects. This is a counterintuitive therapeutic approach and has not yet been widely investigated. The $\beta_{2}$-blocking effect of cardioselective $\beta$-blockers is negligible in therapeutic doses; therefore, there should be no increase in the risk of bronchoconstriction with their use [117].

According to recommendations from the Global Initiative for Chronic Obstructive Pulmonary Disease (GOLD), hypertension, $\mathrm{HF}, \mathrm{CAD}$, and $\mathrm{AF}$ should be treated according to usual guidelines even in patients with severe COPD. If $\beta$-blockers are indicated, a selective $\beta_{1}$-blocker (i.e., bisoprolol, metoprolol, or nebivolol) should be chosen and non-selective blockers avoided, especially in higher doses [118]. The ESC guidelines for HF also encourage the use of selective $\beta_{1}$-blockers in HF with COPD [12]. The Global Initiative for Asthma (GINA) recommendations do not encourage the use of $\beta$-blockers in patients with bronchial asthma; if necessary, treatment should be started under close medical supervision and decisions made on a case-by-case basis (level D evidence). Asthma is not an absolute contraindication for cardioselective $\beta$-blockers for acute coronary events, but a careful risk-benefit assessment should be undertaken (level D evidence) [119].

A Cochrane review of 29 RCTs of cardioselective $\beta_{1^{-}}$ blockers found no adverse respiratory effects in the short term in mild-moderate reversible airway disease or COPD. $\beta_{1}$-Blockers without ISA even showed a nonsignificant trend for increase in respiratory function after $\beta_{2}$-agonist administration compared with placebo [116].

A Cochrane review of 22 RCTs of $\beta_{1}$-selective $\beta$ blockers found no adverse effect on lung function or respiratory symptoms compared with placebo in COPD, even in severe chronic airway obstruction or disease with a reversible obstructive component [114].

A prospective multicenter observational study of current and former smokers found $\beta$-blockers to be associated with a significant reduction in COPD exacerbations regardless of the severity of airflow obstruction [incidence risk ratio (IRR) $0.73, p=0.003]$. The use of other medications for CVD such as CCBs and ACE inhibitors or ARBs was not associated with a reduction in exacerbation risk [120]. Another study found $\beta$-blockers to reduce all-cause mortality and COPD exacerbations when added to established COPD therapy. The additive benefits of $\beta$-blockers were independent of other $\mathrm{CV}$ drugs and history of overt CVD [121].

A number of observational studies found a survival benefit with $\beta$-blocker use in patients with $\mathrm{HF}$ and/or after MI [122-125]. In patients with HF and COPD, the use of the $\beta_{1}$-selective bisoprolol reduced mortality (especially at higher doses) as well as the incidence of congestive HF and COPD exacerbations [122, 123].

Although the observational studies even suggest some benefit with $\beta$-blockers in COPD, RCTs to confirm these findings are lacking. Patients with COPD should not be denied $\beta$-blocker treatment, but careful titration and the use of agents with $\beta_{1}$-selectivity is advised. In bronchial asthma, a benefit-to-risk ratio should be evaluated on an individual basis and $\beta$-blockers avoided if possible.

\section{Conclusions}

The efficacy of $\beta$-blockers has been well demonstrated in several CVDs. These agents were found to considerably reduce mortality in $\mathrm{HF}$ with reduced $\mathrm{EF}$, in $\mathrm{CAD}$ after a MI, and in complicated CVDs, for example with CKD or DM. $\beta$-Blockers may also be beneficial in HF with preserved EF. Furthermore, $\beta$-blockers improve several symptoms of stable angina pectoris and thyrotoxicosis, provide rate control, and prevent new-onset or recurrent $\mathrm{AF}$ in $\mathrm{HF}$, after MI, and following cardiac surgery.

High-risk CV with several comorbidities may also benefit from therapy with $\beta$-blockers. In some cases, such as $\mathrm{CAD}$ or hypertension complicated with $\mathrm{DM}$, the choice of cardioselective $\beta$-blockers or agents with vasodilator activity may be preferable. In CVD complicated with COPD, a $\beta_{1}$-blocker should be the drug of choice when indicated.

Clinical guidelines based on solid evidence give clear recommendations in all the conditions discussed herein. Therapeutic decisions should be evidence based, and patients should not be denied treatment based on personal preconceptions.

The final chapter of the history of $\beta$-blockers has not yet been written. Robust prospective studies are ongoing that will hopefully resolve some of the still divisive issues regarding $\beta$-blockers. Personalized pharmacogenomic approaches might be the way of optimizing CV therapy in future.

\section{Compliance with Ethical Standards}

The authors take responsibility for all aspects of the reliability and freedom from bias of the data presented and their discussed interpretation. 
Funding No external funding was used in the preparation of this manuscript.

Conflict of interest Csaba András Dézsi and Veronika Szentes have no conflicts of interest that are directly relevant to the contents of this manuscript.

Open Access This article is distributed under the terms of the Creative Commons Attribution-NonCommercial 4.0 International License (http://creativecommons.org/licenses/by-nc/4.0/), which permits any noncommercial use, distribution, and reproduction in any medium, provided you give appropriate credit to the original author(s) and the source, provide a link to the Creative Commons license, and indicate if changes were made.

\section{References}

1. Lloyd-Jones D, Adams RJ, Brown TM, et al. Heart Disease and Stroke Statistics-2010 update. A Report From the American Heart Association. Circulation. 2010;121:e1-170.

2. Taylor J, et al. $2013 \mathrm{ESH} / \mathrm{ESC}$ Guidelines for the management of arterial hypertension. Eur Heart J. 2013;34(28):2108-9.

3. Wiysonge CS, Bradley HA, Volmink J, et al. Beta-blockers for hypertension. Cochrane Database Syst Rev. 2012;11:CD002003.

4. Bui AL, Horwich TB, Fonarow GC, et al. Epidemiology and risk profile of heart failure. Nat Rev Cardiol. 2011;8(1):30-41.

5. Gheorghiade M, Colucci WS, Swedberg K. $\beta$-Blockers in chronic heart failure. Circulation. 2003;107:1570-5.

6. Wilcox CS, Tisher CC. Handbook of nephrology and hypertension. Philadelphia: Lippincott Williams \& Wilkins; 2008.

7. Chatterjee S, Biondi-Zoccai G, Abbate A, et al. Benefits of $\beta$ blockers in patients with heart failure and reduced ejection fraction: network meta-analysis. BMJ. 2013;346:f55.

8. Doughty RN, MacMahon S, Sharpe N, et al. Beta-blockers in heart failure: promising or proved? J Am Coll Cardiol. 1994;23(3):814-21.

9. Lechat P, Packer M, Chalon S, et al. Beta-blockers in heart failure: meta-analysis of randomized trials. Circulation. 1998;98:1184-91.

10. Marazzi G, Volterrani M, Caminiti G, et al. Comparative long term effects of nebivolol and carvedilol in hypertensive heart failure patients. J Cardiac Fail. 2011;17(9):703-9.

11. Nodari S, Metra M, Dei Cas L. $\beta$-Blocker treatment of patients with diastolic heart failure and arterial hypertension. A prospective, randomized, comparison of the long-term effects of atenolol vs. nebivolol. Eur J Heart Fail. 2003;5:621-7.

12. McMurray JJ, Adamopoulos S, Anker SD, et al. ESC Guidelines for the diagnosis and treatment of acute and chronic heart failure 2012: the Task Force for the Diagnosis and Treatment of Acute and Chronic Heart Failure 2012 of the European Society of Cardiology. Developed in collaboration with the Heart Failure Association (HFA) of the ESC. Eur Heart J. 2012;33(14): 1787-847.

13. Yancy CW, Jessup M, Bozkurt B, et al. 2013 ACCF/AHA guideline for the management of heart failure: a report of the American College of Cardiology Foundation/American Heart Association Task Force on practice guidelines. Circulation. 2013;128(16):e240-327.

14. Tendera M, Aboyans V, Bartelink ML, et al. ESC Guidelines on the diagnosis and treatment of peripheral artery diseases: document covering atherosclerotic disease of extracranial carotid and vertebral, mesenteric, renal, upper and lower extremity arteries: the Task Force on the Diagnosis and Treatment of
Peripheral Artery Diseases of the European Society of Cardiology (ESC). Eur Heart J. 2011;32(22):2851-906.

15. CIBIS-II Investigators and Committees. The Cardiac Insufficiency Bisoprolol Study II (CIBIS-II): a randomised trial. Lancet. 1999;353(9146):9-13.

16. Packer M, Fowler MB, Roecker EB, et al. Effect of carvedilol on the morbidity of patients with severe chronic heart failure. Results of the carvedilol prospective randomized cumulative survival (COPERNICUS) study. Circulation. 2002;106:2194-9.

17. Hjalmarson A, Goldstein S, Fagerberg B, et al. Effects of controlled-release metoprolol on total mortality, hospitalizations, and well-being in patients with heart failure: the Metoprolol CR/ XL Randomized Intervention Trial in congestive heart failure (MERIT-HF). MERIT-HF Study Group. JAMA. 2000;283(10): 1295-302.

18. Flather MD, Shibata MC, Coats AJ, et al. Randomized trial to determine the effect of nebivolol on mortality and cardiovascular hospital admission in elderly patients with heart failure (SENIORS). Eur Heart J. 2005;26:215-25.

19. Doughty RN, Rodgers A, Sharpe N, et al. Effects of beta-blocker therapy on mortality in patients with heart failure. A systematic overview of randomized controlled trials. Eur Heart J. 1997; 18:560-5.

20. Heidenrich PA, Lee TT, Massie BM. Effect of beta-blockade on mortality in patients with heart failure: a meta-analysis of randomized clinical trials. J Am Coll Cardiol. 1997;30:27-34.

21. Poole-Wilson PA, Swedberg K, Cleland JGF, et al. Comparison of carvedilol and metoprolol on clinical outcomes in patients with chronic heart failure in the Carvedilol Or Metoprolol European Trial (COMET): randomised controlled trial. Lancet. 2003;362:7-13

22. Lin TY, Chen CY, Huang YB. Evaluating the effectiveness of different beta-adrenoceptor blockers in heart failure patients. Int J Cardiol. 2017;230:378-83.

23. Bristow MR, Gilbert EM, Abraham WT, et al. Carvedilol produces dose-related improvements in left ventricular function and survival in subjects with chronic heart failure. Circulation. 1996;94:2807-16.

24. Hori M, Sasayama S, Kitabatake A, et al. Low-dose carvedilol improves left ventricular function and reduces cardiovascular hospitalization in Japanese patients with chronic heart failure: the Multicenter Carvedilol Heart Failure Dose Assessment (MUCHA) trial. Am Heart J. 2004;147(2):324-30.

25. Böhm M, Link A, Cai D, et al. Beneficial association of $\beta$ blocker therapy on recovery from severe acute heart failure treatment: data from the Survival of Patients With Acute Heart Failure in Need of Intravenous Inotropic Support trial. Crit Care Med. 2011;39(5):940-4.

26. Turner RM, Pirmohamed M. Cardiovascular pharmacogenomics: expectations and practical benefits. Clin Pharmacol Ther. 2014;95(3):281-93.

27. Yamamoto K, Origasa H, Hori M, et al. Effects of carvedilol on heart failure with preserved ejection fraction: the Japanese Diastolic Heart Failure Study (J-DHF). Eur J Heart Fail. 2013;15(1):110-8.

28. van Veldhuisen DJ, Cohen-Solal A, Bohm M, et al. Betablockade with nebivolol in elderly heart failure patients with impaired and preserved left ventricular ejection fraction: data from SENIORS (Study of Effects of Nebivolol Intervention on Outcomes and Rehospitalization in Seniors With Heart Failure). J Am Coll Cardiol. 2009;53:2150-8.

29. Bavishi C, Chatterjee S, Ather S, et al. Beta-blockers in heart failure with preserved ejection fraction: a meta-analysis. Heart Fail Rev. 2015;20:193-201. 
30. Liu F, Chen Y, Feng X, et al. Effects of beta-blockers on heart failure with preserved ejection fraction: a meta-analysis. PLoS One. 2014;9(3):e90555.

31. Zhou J, Shi H, Zhang J, et al. Rationale and design of the betablocker in heart failure with normal left ventricular ejection fraction (beta-PRESERVE) study. Eur J Heart Fail. 2010;12(2): 181-5.

32. Badve SV, Roberts MA, Hawley CM, et al. Effects of betaadrenergic antagonists in patients with chronic kidney disease. A systematic review and meta-analysis. J Am Coll Cardiol. 2011;58:1152-61.

33. Wali RK, Iyengar M, Beck GJ, et al. Efficacy and safety of carvedilol in treatment of heart failure with chronic kidney disease a meta-analysis of randomized trials. Circ Heart Fail. 2011;4:18-26.

34. Castagno D, Jhund PS, McMurray JJ, et al. Improved survival with bisoprolol in patients with heart failure and renal impairment: an analysis of the cardiac insufficiency bisoprolol study II (CIBIS-II) trial. Eur J Heart Fail. 2010;12:607-16.

35. Barsness GW, Holmes DR Jr, editors. Coronary Artery Disease: New Approaches without Traditional Revascularization. London: Springer; 2011.

36. Held PH, Yusuf S. Effects of beta-blockers and calcium channel blockers in acute myocardial infarction. Eur Heart J. 1993;14 Suppl F:18-25.

37. Rosendorff C, Lackland DT, Allison M, et al. Treatment of hypertension in patients with coronary artery disease. A scientific statement from the American Heart Association, American College of Cardiology, and American Society of Hypertension. Hypertension. 2015;65:1372-407.

38. Montalescot G, Sechtem U, Achenbach S, et al. 2013 ESC guidelines on the management of stable coronary artery disease. The Task Force on the management of stable coronary artery disease of the European Society of Cardiology. Eur Heart J. 2013;34(38):2949-3003.

39. de Vries RJ, van den Heuvel AF, Lok DJ, et al. Nifedipine gastrointestinal therapeutic system versus atenolol in stable angina pectoris. The NetherlandsWorking Group on Cardiovascular Research (WCN). Int J Cardiol. 1996;57:143-50.

40. Fox KM, Mulcahy D, Findlay I, et al. The Total Ischaemic Burden European Trial (TIBET). Effects of atenolol, nifedipine SR and their combination on the exercise test and the total ischaemic burden in 608 patients with stable angina. The TIBET Study Group. Eur Heart J. 1996;17:96-103.

41. van de Ven LL, Vermeulen A, Tans JG, et al. Which drug to choose for stable angina pectoris: a comparative study between bisoprolol and nitrates. Int J Cardiol. 1995;47:217-23.

42. Bangalore S, Bhatt DL, Steg PG, et al. $\beta$-Blockers and cardiovascular events in patients with and without myocardial infarction. Post hoc analysis from the CHARISMA Trial. Circ Cardiovasc Qual Outcomes. 2014;7:872-81.

43. Husted SE, Ohman EM. Pharmacological and emerging therapies in the treatment of chronic angina. Lancet. 2015;386: 691-701.

44. Huang HL, Fox KA. The impact of beta-blockers on mortality in stable angina: a meta-analysis. Scott Med J. 2012;57(2):69-75.

45. $\beta$-Blocker Heart Attack Trial Research Group. A randomized trial of propranolol in patients with acute myocardial infarction, I: mortality results. JAMA. 1982;247:1707-14.

46. Hjalmarson A, Herlitz J, Holmberg S, et al. The Göteborg metoprolol trial. Effects on mortality and morbidity in acute myocardial infarction. Circulation. 1983;67(6 Pt 2):I26-32.

47. The Norwegian Multicenter Study Group. Timolol-induced reduction in mortality and reinfarction in patients surviving acute myocardial infarction. N Engl J Med. 1981;304:801-7.
48. First International Study of Infarct Survival Collaborative Group. Randomised trial of intravenous atenolol among 16027 cases of suspected acute myocardial infarction: ISIS-1. Lancet. 1986;2(8498):57-66.

49. Yusuf S, Peto R, Lewis J, et al. Beta blockade during and after myocardial infarction: an overview of the randomized trials. Prog Cardiovasc Dis. 1985;27(5):335-71.

50. Chatterjee S, Chaudhuri D, Vedanthan R, et al. Early intravenous beta-blockers in patients with acute coronary syndrome - a meta-analysis of randomized trials. Int $\mathrm{J}$ Cardiol. 2013;168(2):915-21.

51. Roberts R, Rogers WJ, Mueller HS, et al. Immediate versus deferred beta-blockade following thrombolytic therapy in patients with acute myocardial infarction. Results of the Thrombolysis in Myocardial Infarction (TIMI) II-B Study. Circulation. 1991;83(2):422-37.

52. Chen ZM, Pan HC, Chen YP, et al. Early intravenous then oral metoprolol in 45852 patients with acute myocardial infarction: randomised placebo controlled trial. Lancet. 2005;366:1622-32.

53. Dargie HJ, et al. Effect of carvedilol on outcome after myocardial infarction in patients with left-ventricular dysfunction: the CAPRICORN randomised trial. Lancet. 2001;357: 1385-90.

54. Ambrosio G, Flather MD, Böhm M, et al. $\beta$-Blockade with nebivolol for prevention of acute ischaemic events in elderly patients with heart failure. Heart. 2011;97:209-14.

55. Ellison KE, Hafley GE, Hickey K, et al. Effect of $\beta$-blocking therapy on outcome in the Multicenter UnSustained Tachycardia Trial (MUSTT). Circulation. 2002;106:2694-9.

56. Misumida N, Harjai K, Kernis S, et al. Does oral beta-blocker therapy improve long-term survival in ST-segment elevation myocardial infarction with preserved systolic function? A metaanalysis. J Cardiovasc Pharmacol Ther. 2016;21(3):280-5.

57. Schoonderwoerd BA, Smit MD, Pen L, et al. New risk factors for atrial fibrillation: causes of 'not-so-lone atrial fibrillation'. Europace. 2008;10(6):668-73.

58. Gussak I, Antzelevitch C, Wilde AAM, et al., editors. Electrical diseases of the heart: genetics, mechanisms, treatment, prevention. London: Springer; 2013.

59. Camm AJ, Lip GY, De Caterina R, et al. Guidelines for the management of atrial fibrillation. The Task Force for the Management of Atrial Fibrillation of the European Society of Cardiology (ESC). Eur Heart J. 2010;31:2369-429.

60. January CT, Wann LS, Alpert JS, et al. 2014 AHA/ACC/HRS guideline for the management of patients with atrial fibrillation: executive summary: a report of the American College of Cardiology/American Heart Association Task Force on Practice Guidelines and the Heart Rhythm Society. Circulation. 2014;130(23):2071-104.

61. Olshansky B, Rosenfeld LE, Warner AL, et al. The atrial fibrillation follow-up investigation of rhythm management (AFFIRM) study. Approaches to control rate in atrial fibrillation. J Am Coll Cardiol. 2004;43(7):1201-8.

62. Chao T, Liu C, Tuan C, et al. Rate-control treatment and mortality in atrial fibrillation. Circulation. 2015;132:1604-12.

63. Piccini JP, Allen LA. Heart failure complicated by atrial fibrillation. Don't bury the beta-blockers just yet. JACC Heart Fail. 2017.

64. Kao DP, Davis G, Aleong R, et al. Effect of bucindolol on heart failure outcomes and heart rate response in patients with reduced ejection fraction heart failure and atrial fibrillation. Eur J Heart Fail. 2013;15:324-33.

65. Cadrin-Tourigny J, Shohoudi A, Roy D, et al. Decreased mortality with beta-blockers in patients with heart failure and coexisting atrial fibrillation: an AF-CHF substudy. JACC Heart Fail. 2017. 
66. Li SJ, Sartipy U, Lund LH, et al. Prognostic significance of resting heart rate and use of $\beta$-blockers in atrial fibrillation and sinus rhythm in patients with heart failure and reduced ejection fraction. Findings from the Swedish Heart Failure Registry. Circ Heart Fail. 2015;8(5):871-9.

67. Lechat P, Hulot JS, Escolano S, et al. Heart rate and cardiac rhythm relationships with bisoprolol benefit in chronic heart failure in CIBIS II Trial. Circulation. 2001;103(10):1428-33.

68. Kotecha D, Holmes J, Krum H, et al. Efficacy of $\beta$ blockers in patients with heart failure plus atrial fibrillation: an individualpatient data meta-analysis. Lancet. 2014;384:2235-43.

69. University of Birmingham. Rate control therapy evaluation in permanent atrial fibrillation (RATE-AF) [ClinicalTrials.gov identifier NCT02391337]. US National Institutes of Health, ClinicalTrials.gov. https://clinicaltrials.gov/ct2/show/NCT02391337.

70. Kühlkamp V, Schirdewan A, Stangl K, et al. Use of metoprolol $\mathrm{CR} / \mathrm{XL}$ to maintain sinus rhythm after conversion from persistent atrial fibrillation. A randomized, double-blind, placebocontrolled study. J Am Coll Cardiol. 2000;36(1):139-46.

71. van Veldhuisen DJ, Aass H, El Allaf D, et al. Presence and development of atrial fibrillation in chronic heart failure: experiences from the MERIT-HF Study. Eur J Heart Fail. 2006;8(5):539-46.

72. Nasr IA, Bouzamondo A, Hulot JS, et al. Prevention of atrial fibrillation onset by beta-blocker treatment in heart failure: a meta-analysis. Eur Heart J. 2007;28(4):457-62.

73. Swedberg K, Olsson LG, Charlesworth A, et al. Prognostic relevance of atrial fibrillation in patients with chronic heart failure on long-term treatment with beta-blockers: results from COMET. Eur Heart J. 2005;26(13):1303-8.

74. McMurray J, Køber L, Robertson M, et al. Antiarrhythmic effect of carvedilol after acute myocardial infarction: results of the Carvedilol Post-Infarct Survival Control in Left Ventricular Dysfunction (CAPRICORN) trial. J Am Coll Cardiol. 2005;45(4):525-30.

75. Arsenault KA, Yusuf AM, Crystal E, et al. Interventions for preventing post-operative atrial fibrillation in patients undergoing heart surgery (review). Cochrane Database Syst Rev. 2013;1:003611.

76. Burgess DC, Kilborn MJ, Keech AC, et al. Interventions for prevention of post-operative atrial fibrillation and its complications after cardiac surgery: a meta-analysis. Eur Heart $\mathrm{J}$. 2006;27(23):2846-57.

77. Sakamoto A, Hamasaki T, Kitakaze M, et al. Perioperative landiolol administration reduces atrial fibrillation after cardiac surgery: a meta-analysis of randomized controlled trials. Adv Ther. 2014;31(4):440-50.

78. Wang HS, Wang ZW, Yin ZT, et al. Carvedilol for prevention of atrial fibrillation after cardiac surgery: a meta-analysis. PLoS One. 2014;9(4):e94005.

79. Blessberger H, Kammler J, Domanovits H, et al. Perioperative beta-blockers for preventing surgery-related mortality and morbidity. Cochrane Database Syst Rev. 2014;9:004476.

80. Wijeysundera DN, Duncan D, Nkonde-Price C, et al. Perioperative beta blockade in noncardiac surgery: a systematic review for the 2014 ACC/AHA guideline on perioperative cardiovascular evaluation and management of patients undergoing noncardiac surgery. A Report of the American College of Cardiology/American Heart Association Task Force on Practice Guidelines. Circulation. 2014;130(24):2246-64.

81. Gürdoğan M, Ari H, Tenekecioğlu E, et al. Predictors of atrial fibrillation recurrence in hyperthyroid and euthyroid patients. Arq Bras Cardiol. 2016;106(2):84-91.

82. Bahn Chair RS, Burch HB, Cooper DS, et al. Hyperthyroidism and other causes of thyrotoxicosis: management guidelines of the American Thyroid Association and American Association of Clinical Endocrinologists. Thyroid. 2011;21(6):593-646.

83. Tagami T, Yambe Y, Tanaka T, et al. Short-term effects of $\beta$ adrenergic antagonists and methimazole in new-onset thyrotoxicosis caused by Graves' disease. Intern Med. 2012;51(17):2285-90.

84. Trzepacz PT, Klein I, Roberts M, et al. Graves' disease: an analysis of thyroid hormone levels and hyperthyroid signs and symptoms. Am J Med. 1989;87(5):558-61.

85. Ventrella SM, Klein I. Beta-adrenergic receptor blocking drugs in the management of hyperthyroidism. Endocrinologist. 1994;4(5):391-9.

86. Cruickshank JM. Are we misunderstanding beta-blockers. Int J Cardiol. 2007;120(1):10-27.

87. Aubert R. Diabetes in America. DIANE Publishing, $2^{\text {nd }}$ edition. NIH Publication No. 95-1468. National Institutes of Health, National Institute of Diabetes and Digestive and Kidney Diseases; 1995.

88. Jacob S, Rett K, Henriksen EJ, et al. Antihypertensive therapy and insulin sensitivity: do we have to redefine the role of beta blocking agents? Am J Hypertens. 1998;11(10):1258-65.

89. Gottlieb S, McCarter RJ, Vogel RA, et al. Effect of betablockade on mortality among high-risk and low-risk patients after myocardial infarction. N Engl J Med. 1998;339(8):489-97.

90. Landray MJ, Toescu V, Kendall MJ, et al. The cardioprotective role of $\beta$-blockers in patients with diabetes mellitus. J Clin Pharm Ther. 2002;27(4):233-42.

91. Shorr RI, Ray WA, Daugherty JR, et al. Antihypertensives and the risk of serious hypoglycemia in older persons using insulin or sulfonylureas. JAMA. 1997;278(1):40-3.

92. Hirst JA, Farmer AJ, Feakins BG, et al. Quantifying the effects of diuretics and $\beta$-adrenoceptor blockers on glycaemic control in diabetes mellitus - a systematic review and meta-analysis. Br J Clin Pharmacol. 2015;79(5):733-43.

93. Dominguez LJ, Barbagallo M, Jacober SJ, et al. Bisoprolol and captopril effects on insulin receptor tyrosine kinase activity in essential hypertension. Am J Hypertens. 1997;10:1349-55.

94. Kostis JB, Sanders M. The association of heart failure with insulin resistance and the development of type 2 diabetes. Am $\mathbf{J}$ Hypertens. 2005;18:731-7.

95. Ladage D, Reidenbach C, Rieckeheer E, et al. Nebivolol lowers blood pressure and increases weight loss in patients with hypertension and diabetes in regard to age. J Cardiovasc Pharmacol. 2010;56(3):275-81.

96. Poirier L, Cléroux J, Nadeau A, et al. Effects of nebivolol and atenolol on insulin sensitivity and haemodynamics in hypertensive patients. J Hypertens. 2001;19(8):1429-35.

97. Rosendorff C. Beta-blocking agents with vasodilator activity. J Hypertens. 1993;11(4):S37-40.

98. Seguchi H, Nakamura H, Aosaki N, et al. Effects of carvedilol on serum lipids in hypertensive and normotensive subjects. Eur J Clin Pharmacol. 1990;38(Suppl 2):S139-42.

99. Wang B, Song WH, Liu GZ, et al. The effect long-term administration of a selective beta1 blocker bisoprolol on glucose metabolism in patients with essential hypertensive and type 2 diabetes mellitus. Zhonghua Nei Ke Za Zhi. 2005;44(7):503-5.

100. Torre JJ, Bloomgarden ZT, Dickey RA, et al. American Association of Clinical Endocrinologists Medical guidelines for clinical practice for the diagnosis and treatment of hypertension. Endocr Pract. 2006;12(2):193-222.

101. Rydén L, Grant PJ, Anker SD, et al. ESC Guidelines on diabetes, pre-diabetes, and cardiovascular diseases developed in collaboration with the EASD: the Task Force on diabetes, prediabetes, and cardiovascular diseases of the European Society of Cardiology (ESC) and developed in collaboration with the 
European Association for the Study of Diabetes (EASD). Eur Heart J. 2013;34(39):3035-87.

102. Bangalore S, Parkar S, Grossman E, et al. A meta-analysis of 94,492 patients with hypertension treated with beta blockers to determine the risk of new-onset diabetes mellitus. Am J Cardiol. 2007;100(8):1254-62.

103. UK Prospective Diabetes Study Group. Tight blood pressure control and risk of macrovascular and microvascular complications in type 2 diabetes: UKPDS 38. BMJ. 1998;317(7160): 703-13.

104. UK Prospective Diabetes Study Group. Efficacy of atenolol and captopril in reducing risk of macrovascular and microvascular complications in type 2 diabetes: UKPDS 39. BMJ. 1998;317(7160):713-20.

105. Bell DS, Lukas MA, Holdbrook FK, et al. The effect of carvedilol on mortality risk in heart failure patients with diabetes: results of a meta-analysis. Curr Med Res Opin. 2006;22(2):287-96.

106. Haas SJ, Vos T, Gilbert RE, et al. Are beta-blockers as efficacious in patients with diabetes mellitus as in patients without diabetes mellitus who have chronic heart failure? A meta-analysis of large-scale clinical trials. Am Heart J. 2003;146(5): 848-53.

107. Shekelle PG, Rich MW, Morton SC, et al. Efficacy of angiotensin-converting enzyme inhibitors and beta-blockers in the management of left ventricular systolic dysfunction according to race, gender and diabetic status: a meta-analysis of major clinical trials. J Am Coll Cardiol. 2003;41(9):1529-38.

108. Deedwania PC, Giles TD, Klibaner M, et al. Efficacy, safety and tolerability of metoprolol $\mathrm{CR} / \mathrm{XL}$ in patients with diabetes and chronic heart failure: experiences from MERIT-HF. Am Heart J. 2005;149(1):159-67.

109. Domanski M, Krause-Steinrauf H, Deedwania P, et al. The effect of diabetes on outcomes of patients with advanced heart failure in the BEST trial. J Am Coll Cardiol. 2003;42(5):914-22.

110. Packer M, Coats AJ, Fowler MB, et al. Effect of carvedilol on survival in severe chronic heart failure. $\mathrm{N}$ Engl $\mathrm{J}$ Med. 2001;344(22):1651-8.

111. Malmberg K, Herlitz J, Hjalmarson A, et al. Effects of metoprolol on mortality and late infarction in diabetics with suspected acute myocardial infarction. Retrospective data from two large studies. Eur Heart J. 1989;10(5):423-8.

112. Kjekshus J, Gilpin E, Cali G, et al. Diabetic patients and betablockers after acute myocardial infarction. Eur Heart J. 1990;11:43-50.

113. Jonas M, Reicher-Reiss H, Boyko V, et al. Usefulness of betablocker therapy in patients with non-insulin-dependent diabetes mellitus and coronary artery disease. Bezafibrate Infarction Prevention (BIP) Study Group. Am J Cardiol. 1996;77(15):1273-7.

114. Salpeter SR, Ormiston TM, Salpeter EE. Cardioselective betablockers for chronic obstructive pulmonary disease. Cochrane Database Syst Rev. 2005;4:CD003566.

115. Lipworth B, Skinner D, Devereux G, et al. Underuse of $\beta$ blockers in heart failure and chronic obstructive pulmonary disease. Heart. 2016;102:1909-14.

116. Salpeter S, Ormiston T, Salpeter E. Cardioselective betablockers for reversible airway disease. Cochrane Database Syst Rev. 2002;4:CD002992.

117. Ormiston TM, Salpeter SR. Beta-blocker use in patients with congestive heart failure and concomitant obstructive airway disease: moving from myth to evidence-based practice. Heart Fail Monit. 2003;4(2):45-53.

118. Vestbo J, Hurd SS, Agustí AG, et al. Global strategy for the diagnosis, management, and prevention of chronic obstructive pulmonary disease: GOLD executive summary. Am J Respir Crit Care Med. 2013;187:347-65.

119. Global Initiative for Asthma. Global Strategy for Asthma Management and Prevention; 2016. http://www.ginasthma.org

120. Bhatt SP, Wells JM, Kinney GL, et al. $\beta$-Blockers are associated with a reduction in COPD exacerbations. Thorax. 2016;71(1):8-14.

121. Short PM, Lipworth SIW, Elder DHJ, et al. Effect of $\beta$ blockers in treatment of chronic obstructive pulmonary disease: a retrospective cohort study. BMJ. 2011;342:d2549.

122. Su VY, Chang Y, Hu Y, et al. Carvedilol, bisoprolol, and metoprolol use in patients with coexistent heart failure and chronic obstructive pulmonary disease. Medicine (Baltimore). 2016;95(5):e2427.

123. Kubota Y, Asai K, Furuse E, et al. Impact of $\beta$-blocker selectivity on long-term outcomes in congestive heart failure patients with chronic obstructive pulmonary disease. Int $\mathrm{J}$ COPD. 2015;10:515-23.

124. Andell P, Erlinge D, Smith JG, et al. $\beta$-Blocker use and mortality in COPD patients after myocardial infarction: a Swedish nationwide observational study. J Am Heart Assoc. 2015;4:e001611.

125. Coiro S, Girerd N, Rossignol P, et al. Association of betablocker treatment with mortality following myocardial infarction in patients with chronic obstructive pulmonary disease and heart failure or left ventricular dysfunction: a propensity matched-cohort analysis from the High-Risk Myocardial Infarction Database Initiative. Eur J Heart Fail. 2017;19(2):271-9. doi:10. 1002/ejhf.647. 